Research Paper

\title{
Antenatal Betamethasone Induces Increased Surfactant Proteins and Decreased Foxm 1 Expressions in Fetal Rabbit Pups
}

\author{
Yong-Sung Choi ${ }^{1}$, Chae-Young Kim ${ }^{1}$, Hye Kyung Chang ${ }^{2}$, Young Joo Lee ${ }^{3}$, Sung-Hoon Chung ${ }^{\circledR}$ \\ 1. Department of Pediatrics, Kyung Hee University School of Medicine, Seoul, Republic of Korea \\ 2. Department of Surgery, Kyung Hee University School of Medicine, Seoul, Republic of Korea \\ 3. Department of Obstetrics and Gynecology, Kyung Hee University School of Medicine, Seoul, Republic of Korea \\ $\square$ Corresponding author: Sung-Hoon Chung, MD, PhD. Address: Kyung Hee university hospital, 23 Kyungheedae-ro, Dongdaemun-gu, Seoul, Korea. Zip \\ code: 02447. E-mail: pedc@hanmail.net; Tel.: 822958 2921; Fax: 8229588299
}

(c) The author(s). This is an open access article distributed under the terms of the Creative Commons Attribution License (https://creativecommons.org/licenses/by/4.0/). See http:/ /ivyspring.com/terms for full terms and conditions.

Received: 2021.05.04; Accepted: 2021.07.14; Published: 2021.07.25

\begin{abstract}
Introduction: Antenatal steroid improves respiratory distress syndrome in preterm infants. The molecular mechanism of the process is not well established. The aim of this study is to investigate the possible association between antenatal steroid and fetal Forkhead box Ml (Foxml) expression.

Materials and methods: An animal study using mated pregnant New Zealand white rabbits and their fetuses was designed. Fourteen mother rabbits were assigned to four groups to undergo a cesarean section. In groups 1, 2, and 3, preterm pups were harvested on day 27 of gestation. In group 4, term pups were harvested on day 31. Antenatal maternal intramuscular injection was performed in groups 2 (normal saline) and 3 (betamethasone). Using qRT-PCR and Western blot, mRNA transcription and protein expression of surfactant protein (SP) A, B, C, and Foxml were compared between the pups of those four groups.

Results: Sixty two fetal rabbits were harvested. One-way ANOVA test showed higher mRNA transcription of SPs in groups 3 and 4 than groups 1 and 2. Significantly lower Foxm 1 mRNA transcription and protein expression were observed in group 3 or 4 compared with group 1 or 2 .

Conclusion: Decreased Foxm 1 expression was associated in an antenatal betamethasone animal model.

Key words: Respiratory distress syndrome, newborn; Pulmonary surfactant; Pulmonary surfactant associated proteins; Forkhead box M1 protein, human
\end{abstract}

\section{Introduction}

Despite remarkable advances in neonatal intensive care, respiratory distress syndrome (RDS) is still a leading cause of death in preterm infants [1-3]. In the era of improved outcomes of RDS along with introduction of pulmonary surfactant therapy and early application of non-invasive ventilation, maternal antenatal steroid has remained as another mainstay in lowering the mortality and morbidity [4]. Maternal antenatal steroid confers acute changes in fetal lung tissue, which include decreased alveolar septation, mesenchymal thinning, and increased lung compliance and gas-exchange $[5,6]$. Several mechanisms in those changes appear to be explainable, such as maternal cortisol effect, the stress response of the fetus, or the influence of chorioamnionitis $[7,8]$.

In addition, some studies regarding embryonal development of pulmonary tissue reported the importance of the expression of Forkhead box M1 (Foxm1). They studied the association of Foxm1 with preterm rabbit lung [9]. Foxm1 protein is one of extensive transcription factors sharing its homology in the Winged helix/forkhead DNA binding domain. It directly influences mitosis and its deficient hepatoblasts and cardiomyocytes showed decreased DNA replication due to accumulation of polypoid phenotype and failed to progress to mitosis in the end 
[10-12]. Interestingly, it involves lung development. Foxm1 knock-out mice showed severe hypertrophy of arteriolar smooth muscle cells in lung tissue and deficient platelet endothelial cell adhesion molecules in peripheral pulmonary capillaries [13]. In another study, conditioned deletion of Foxm1 was induced in mouse pulmonary tissues, which led to failure of lung development with decreased expression of SP-A, B, C, and $\mathrm{D}[14]$. Remarkably, Foxm1 has a striking characteristic, it is enhanced during cell proliferation, and later, is extinguished when cell differentiation is over $[15,16]$.

Therefore, in the current study, we hypothesized that there should be certain relationship between antenatal steroid and FOXM1 expression in a fetal rabbit model animal experiment.

\section{Materials and methods}

The animal experiment was approved by the Institutional Animal Care and Use Committee of Kyung Hee University Hospital at Gangdong. All surgical procedures were performed under anesthetic agent Zoletil ${ }^{\circledR}$ (tiletamine + zolazepam, $15 \mathrm{mg} / \mathrm{kd}$ ). An antenatal maternal steroid injection model in preterm delivery groups was designed. Sixty two rabbit pups were harvested from 14 pregnant female New Zealand white rabbits.

\section{Antenatal preparation of pregnant rabbits}

In terms of lung maturation, neonatal pups were categorized into four groups, basically into preterm (Group 1, 2, and 3) or term (Group 4). Delivery was scheduled by cesarean section for controlled condition on day 27 in preterm groups and day 31 in the term group. Controls were Group 1 as a preterm control and Group 4 as a term control. Mothers of Group 2 pups underwent antenatal normal saline injection on days 25 and 26, which was for the sham procedure. Mothers of Group 3 pups (study group) received an interventional antenatal betamethasone injection on days 25 and 26 (Figure 1).

The antenatal injection preparations for the maternal rabbits were as follows: Betamethasone, 0.05 $\mathrm{mg} / \mathrm{kg}$ and normal saline, $0.0125 \mathrm{ml} / \mathrm{kg}$, which were the same by volumes. The injections were only administered intramuscularly in groups 2 and 3 and the schedule for days 25 and 26 were mimicked like human protocol.

\section{Preparation of lung tissues from newborn rabbit pups}

All the newborn pups underwent tracheostomy using an 18-gauge angiocatheter. Forced aeration of $0.5 \mathrm{ml}$ was applied 10 times using a $1.0 \mathrm{ml}$ syringe before obtaining the lung tissues. The lung tissues were used for the mRNA analysis, Western blot, and histologic findings. Total mRNA extractions were performed using the RNeasy ${ }^{\circledR}$ mini kit Qiagen.

\section{Measurement of surfactant protein (SP) A, B, $C$ and Foxm I level}

Quantitative real-time RT-PCR (qRT-PCR) was used for measurement of the mRNA level and Western blot was used for the protein expression. SP-A, B, and C mRNA quantitation was performed according to the SYBR ${ }^{\circledR}$ Green I protocol. Primers were purchased from BIONEER (Daejeon, South Korea). The PCR protocol was performed at $95^{\circ} \mathrm{C}$ for 15 seconds denaturation and $56.6^{\circ} \mathrm{C}$ for 20 seconds cooling and $72^{\circ} \mathrm{C}$ for 30 seconds synthesis and repeated 35 times. For Western blot, we used human Foxm1 protein antibody $\left(\right.$ Abcam ${ }^{\circledR}$, Cambridge, UK) for primary antibody and peroxidase liked mouse antibody (Santa Cruz Biotechnology, Inc., USA) for the secondary. The concentration was based on group 4 as 1.0 and quantified by $\beta$-actin values.

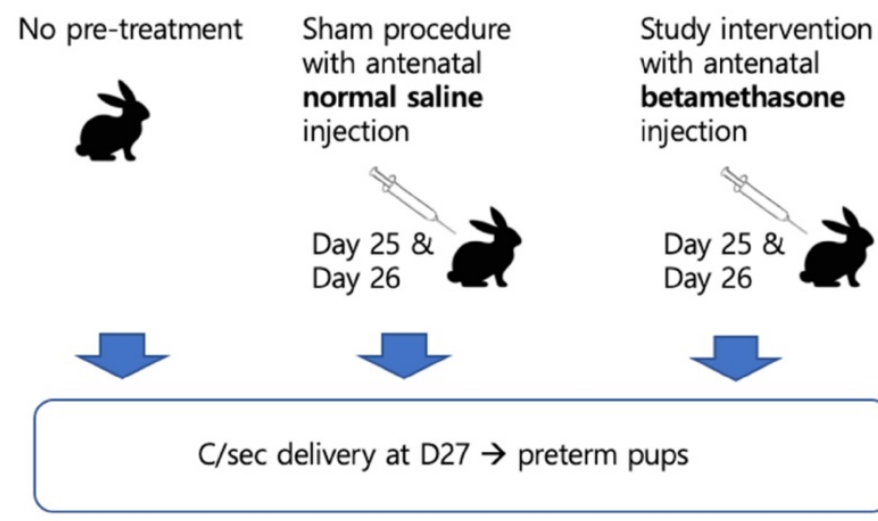

Group 1

Group 2

Group 3

Figure 1. Scheme of the current study. 


\section{Design of rabbit Foxm l primer}

There is no known Foxm1 sequence in rabbit, therefore we designed the primer. The Foxm1 sequence of mouse (Genbank, accession number: NM_008021.4) and human (Genbank accession number: NW_003159267.1) were matched with the whole base pair of the $8^{\text {th }}$ chromosome of rabbit (Genbank accession number: NW_003159267.1) and then base pairs of homology were found. Four pairs of primers were designed via Primer3 website (http://frodo.wi.mit.edu/primer3/) and the most prominent band that was matched and designed with human Foxm 1 sequence was selected. Finally we used anti-sense $5^{\prime}$-agg aaa gct gac ttg gaa ac- $3^{\prime}$ and sense $5^{\prime}$-gtg cat ggt ttc ttc ttc cag- $3^{\prime}$ pair.

\section{Histologic preparation}

Some of the lung tissues of harvested pups were observed by histological method. The tissues were fixed with $10 \%$ buffered formalin and a paraffin block was made for staining Hematoxylin and Eosin (H\&E). The aerated area ratio was viewed using the IBAS 2000 system (Karl Zeiss, Jena, Germany), which was calculated by ImageJ software (LOCI, University of Wisconsin). We tried to obtain the tissue slides in the midportion of the extracted specimens.

\section{Electron microscopic examination}

Electron microscopy was also performed (FE-SEM, HITACHI S-800, Japan). We chose the best quality images from some of the slides.

\section{Statistical analysis}

One-way ANOVA was used to compare the values for four groups. Turkey HSD was used as a posthoc test. Linear regression analysis was performed between SP mRNA and Foxm1 protein expression. Measured values were expressed as mean \pm standard deviation. $P$ values $<0.05$ were considered significant.

\section{Results}

Sixty two rabbit pups were harvested from 14 mother rabbits (Table 1). There were no serious adverse effects such as maternal death, spontaneous preterm delivery, or fetal death. The mean birth weights of groups were $37.5 \pm 4.2,39.3 \pm 4.2,32.3 \pm 6.5$, and $49.4 \pm 6.6$ grams, respectively. Mean birth weight was significantly lower in Group 3 compared with group $2(p<0.001)$.
Table 1. Rabbit pups grouping.

\begin{tabular}{lllll}
\hline & Group 1 & Group 2 & Group 3 & Group 4 \\
\hline Pregnant rabbit & 4 & 3 & 3 & 4 \\
Antenatal treatment & not done & normal saline & betamethasone & not done \\
Delivery* & D27 & D27 & D27 & D31 \\
Pup & 16 & 16 & 14 & 16 \\
Pup weight (g) & $37.5 \pm 2.49$ & $39.30 \pm 4.20$ & $33.00 \pm 6.54$ & $49.44 \pm 6.56$ \\
\hline *, delivery date after mating. & & &
\end{tabular}

qRT-PCR of SP-A, B and C, shown in Figure 2, were significantly higher in betamethasone (Group 3) pups compared to normal saline group (Group 2, $p=0.007,0.007$, and 0.022) and in term (Group4) pups compared to preterm control (Group 1, $p=0.004,0.004$, and 0.007). No significant difference was observed between groups 3 and 4 . The opposite results were obtained with Foxm1 levels. Significantly higher mRNA qRT-PCT was observed in Group 1 compared to Group $4(p=0.001)$ and in Group 2 compared to Group 3 ( $p=0.006$, Figure 3). Western blot of Foxm1 in Group 1 was increased compared to Group 4 $(p=0.001)$ and in Group 2 compared to Group 3 $(p=0.019$, Figure 3$)$.

Linear regression performed between Foxm1 and surfactant proteins showed negative correlations between Foxm 1 and SP-A $\left(\mathrm{R}^{2}=0.108, p=0.036\right)$, SP-B $\left(\mathrm{R}^{2}=0.149, p=0.007\right)$, and SP-C $\left(\mathrm{R}^{2}=0.339, p=0.018\right)$ (Figure 4).

Examples of histologic findings are shown in Figures 5 and 6. Although these are just some examples of the appearance of histologic findings, we could examine the microscopy. We selected four H\&E stained slides to show aerated area ratios in Figure 5. Electron microscopy showed type 2 pneumocytes from one of group 2 and group 3 . Abundant lamella bodies can be seen in cytoplasm of betamethasone treated pups (Figure 6).

\section{Discussion}

Our animal model confirmed that antenatal betamethasone induced an increase in the level of SPA, B, and C. Numerous studies showing that antenatal steroid promotes surfactant protein synthesis have been reported $[8,17]$. In other words, the higher the level of SPs, the larger the amount of pulmonary surfactant. This is consistent with the role of antenatal steroids in lowering severity of RDS. In terms of molecular association, we chose the Foxm1 gene. We hypothesized that Foxm1 expression has a certain relationship with the expression of SPs in the fetal lung maturation process, based on some evidence that it involves branching morphogenesis and vasculogenesis in fetal lung development [13]. 


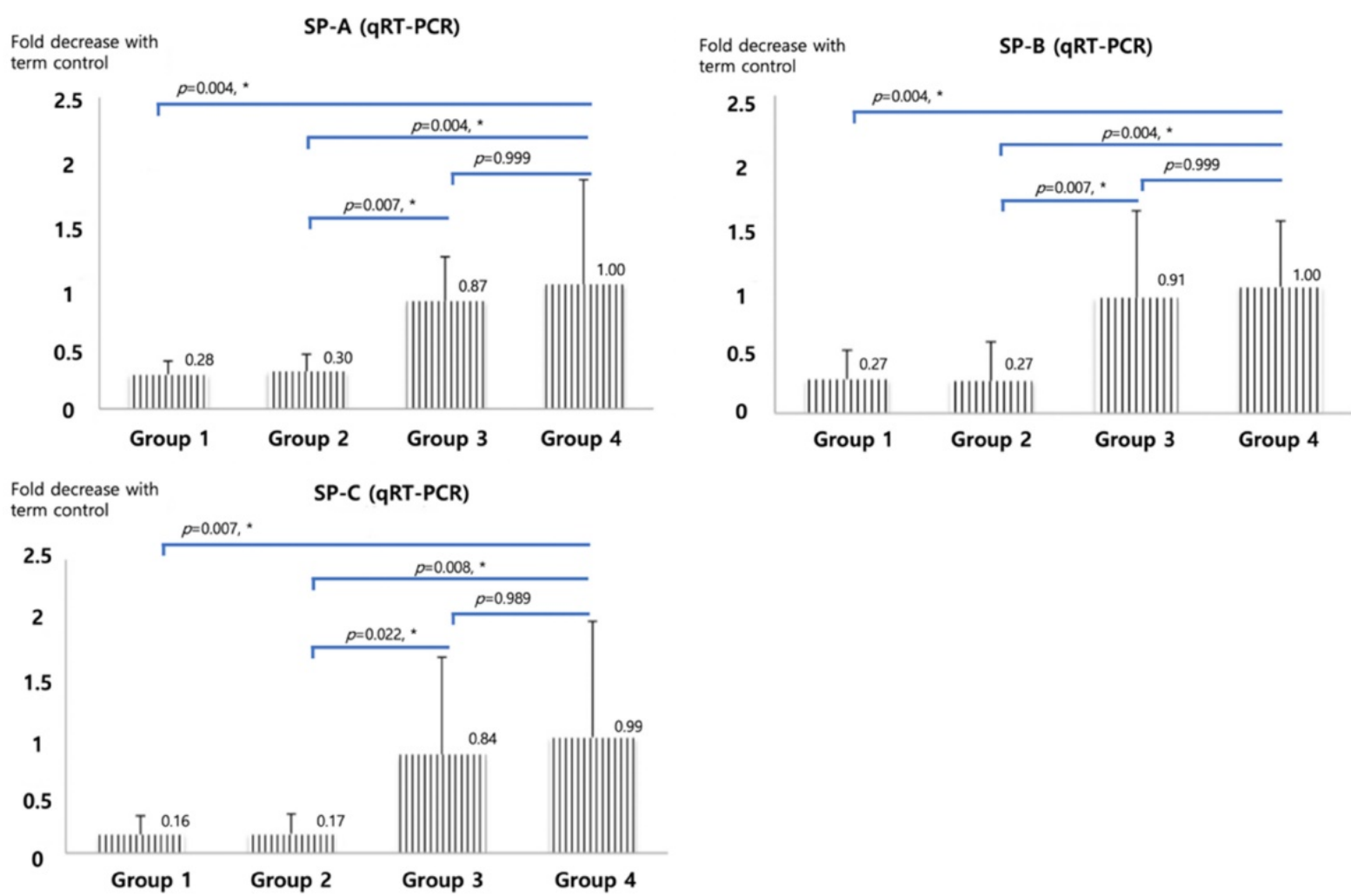

Figure 2. Surfactant protein A, B, and C mRNA qRT-PCR. The diagram was based on the mean values and error bar. N=12. One-way ANOVA test was used.
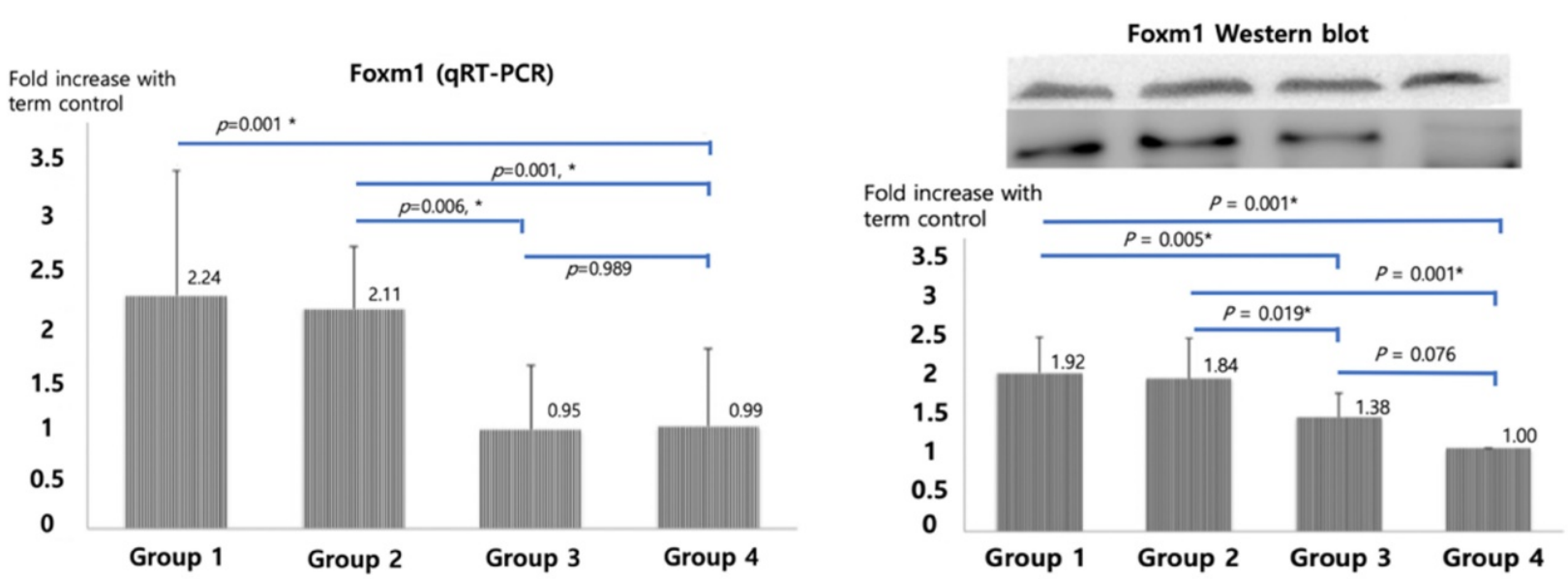

Figure 3. Foxm 1 mRNA qRT-PCR and Western blot results. The diagram was based on the mean values and error bar. N=12. One-way ANOVA test was used.
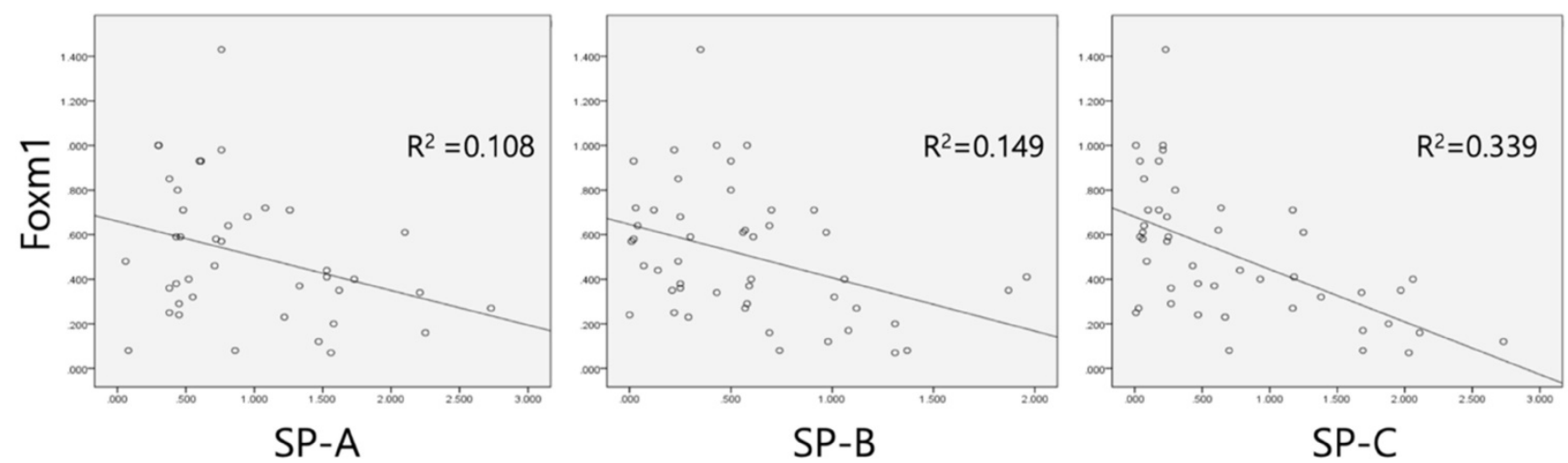

Figure 4. Linear regression analysis between SP-A, -B, -C and Foxm1. Negative correlation was observed between surfactant protein A, B, and C and Foxm 1. Values as qRT-PCR results were used. 


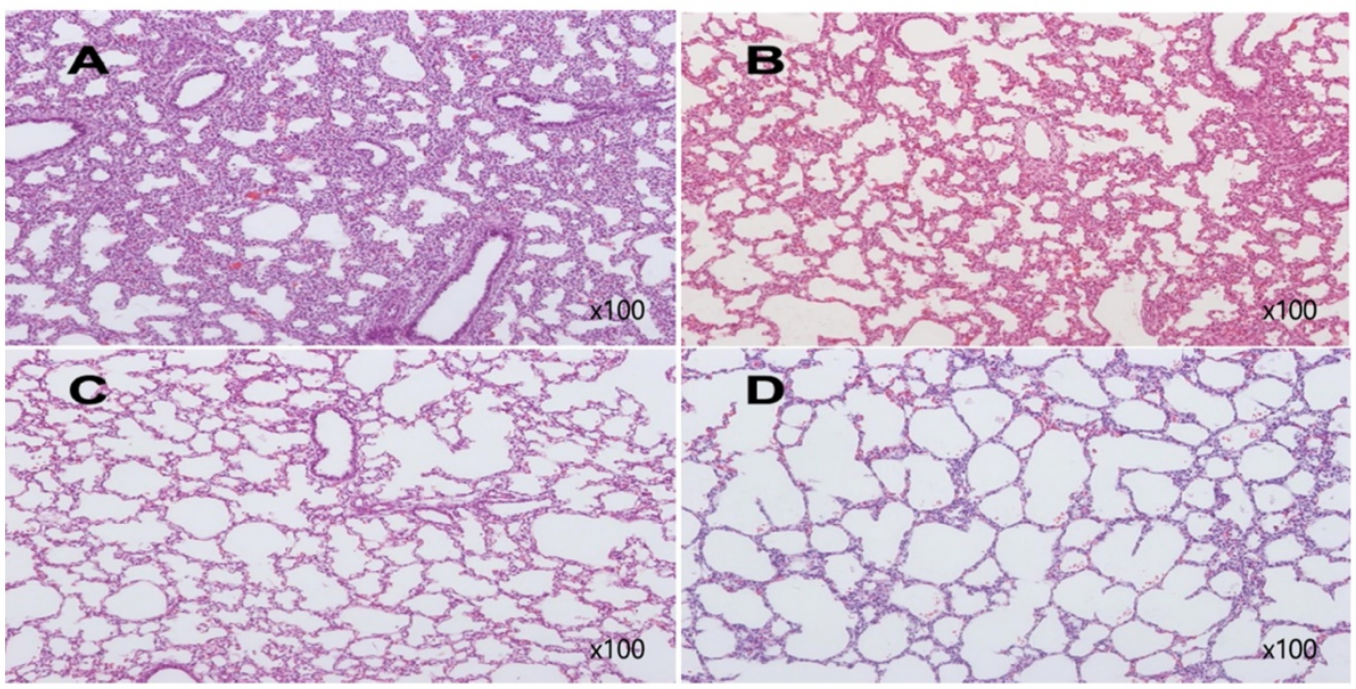

Figure 5. H\&E stain of rabbit fetal lung tissues. A from one of group 1 , Aerated area ratio $(A A R)=0.27, B$ from one of group $2, A A R=0.3, C$ from one of group $3, A A R=0.85, D$ from one of group $4, A A R=0.95$. $A$ and $B$ show decreased alveolarization. $C$ shows much thinner alveolar septae comparable to those of term rabbit newborn, $D$.
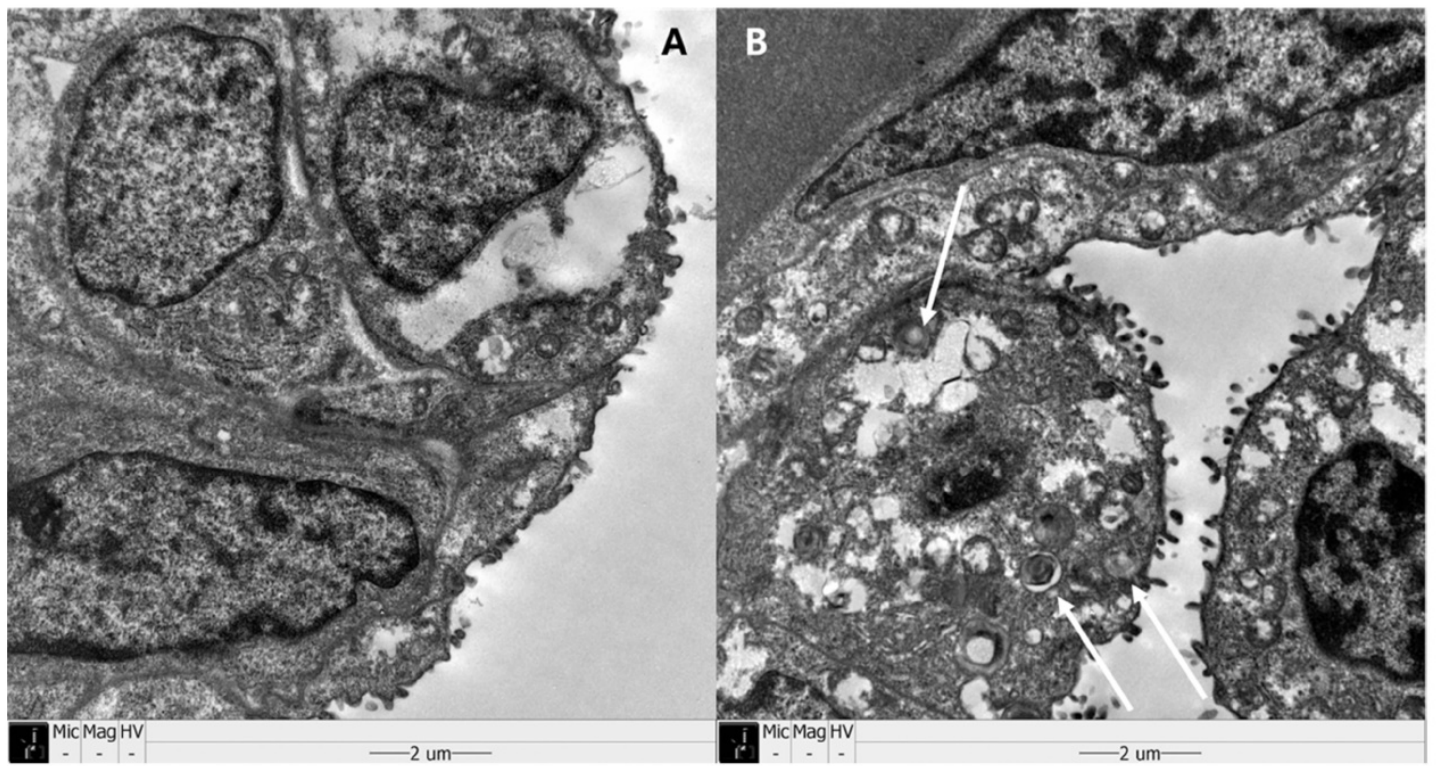

Figure 6. Sanning electromicroscopy (SEM) revealed type Il pneumocytes. White arrows show abundant lamella bodies in one of group 3 (B), different from one of group 2 (A).

It is evident that Foxm1 regulates mitosis in the process of cell cycle based on numerous studies [10-12]. In terms of lung maturation, Kalin et al [14] deleted Foxm 1 conditionally in respiratory epithelium and it resulted in lung tissue maturation defects. We observed that Foxm1 remained decreased in term and betamethasone group pups compared to sustained high in control preterm groups. It implicates that Foxm1 participates in the maturation process, and rapidly diminishes after the maturation is over. It can be explained by that Foxm1 promotes S-phase and M-phase entry of mitosis and facilitates cell proliferation $[15,16]$. It is not known whether Foxm1 has a direct influence on SPs or other alveolar thinning processes. However, we could find the negative correlation between Foxm1 and SPs induced by antenatal betamethasone.

We used the preterm rabbit model, which is compatible with the RDS, artificial pulmonary surfactant, and antenatal steroid study, because it is very close to human fetal lung development $[17,18]$. D27 corresponds to the human canalicular stage of lung development, and D31 to the saccular or alveolar stage [19]. We could observe the effect of betamethasone on fetal lung by the histologic finding and induction of surfactant proteins. Interestingly, recognizable fetal weight loss was observed in the betamethasone group. In human and animal studies, antenatal steroid resulted in fetal weight loss $[5,20]$. In our study, the average birth weight of the fetal pups of the betamethasone group was $16 \%$ lower than that of the normal saline control group $(33.0 \pm 6.5 \mathrm{~g}$ vs. 
$39.3 \pm 4.2 \mathrm{~g}, p<0.001$, Table 1). Thus, we can assume that our antenatal steroid injection to mother rabbits had pharmacological effects on their fetuses.

Our study has several limitations. The sample size is relatively small. We did not examine specific surfactant synthesis transporter regarding Foxm1. However, ours is the first study to determine the association between Foxm1 and antenatal steroid injection in an animal model.

\section{Acknowledgments}

This work was supported by a grant from Kyung Hee University in 2017 (KHU-20171284).

\section{Competing Interests}

The authors have declared that no competing interest exists.

\section{References}

1. Angus DC, Linde-Zwirble WT, Clermont G, Griffin MF, Clark RH. Epidemiology of neonatal respiratory failure in the United States: projections from California and New York. Am J Respir Crit Care Med 2001:164:1154-60.

2. Bhakoo ON, Narang A, Karthikeyan G, Kumar P. Spectrum of respiratory distress in very low birthweight neonates. Indian J Pediatr 2000;67:803-4.

3. Agustines LA, Lin YG, Rumney PJ, Lu MC, Bonebrake R, Asrat T, et al Outcomes of extremely low-birth-weight infants between 500 and $750 \mathrm{~g}$. Am J Obstet Gynecol 2000;182:1113-6.

4. Roberts D, Dalziel S. Antenatal corticosteroids for accelerating fetal lung maturation for women at risk of preterm birth. Cochrane Database Syst Rev 2006;19:CD004454.

5. Jobe AH. Animal models of antenatal corticosteroids: clinical implications. Clin Obstet Gynecol 2003;46:174-89.

6. Ikegami $\mathrm{M}$, Jobe $\mathrm{AH}$, Seidner S, Yamada T. Gestational effects of corticosteroids and surfactant in ventilated rabbits. Pediatr Res 1989;25:32-7.

7. Muglia LJ, Bae DS, Brown TT, Vogt SK, Alvarez JG, Sunday ME, et al. Proliferation and differentiation defects during lung development in corticotropin-releasing hormone-deficient mice. Am J Respir Cell Mol Biol 1999;20:181-8.

8. Tabor BL, Lewis JF, Ikegami M, Polk D, Jobe AH. Corticosteroids and fetal intervention interact to alter lung maturation in preterm lambs. Pediatr Res 1994;35:479-83.

9. Hanh WH, Chang JY, Lee KS, Bae CW. Decreased Expression of Surfactant Protein Genes is Associated with the Increased Expression of Forkhead Box M1 Gene in the Fetal Lung Tissues of Premature Rabbits. Yonsei Med J 2013;54:1422-9.

10. Costa RH. FoxM1 dances with mitosis. Nat Cell Biol 2005;7:108-10.

11. Korver W, Schilham MW, Moerer P, van den Hoff MJ, Dam K, Lamers WH, et al. Uncoupling of $\mathrm{S}$ phase and mitosis in cardiomyocytes and hepatocytes lacking the winged-helix transcription factor Trident. Curr Biol 1998;8:132730 .

12. Ramakrishna S, Kim I-M, Petrovic V, Malin D, Wang IC, Kalin TV, et al. Myocardium defects and ventricular hypoplasia in mice homozygous null for the Forkhead Box M1 transcription factor. Dev Dyn 2007;236:1000-13.

13. Kim I, Ramakrishna S, Gusarova G, Yoder H, Costa R, Kalinichenko V. The forkhead box M1 transcription factor is essential for embryonic development of pulmonary vasculature. J Biol Chem 2005;280:22278-86.

14. Kalin TV, Wang I-C, Meliton L, Zhang Y, Wert SE, Ren X, et al. Forkhead Box $\mathrm{m} 1$ transcription factor is required for perinatal lung function. Proc Natl Acad Sci USA 2008;105:19330-5.

15. Ye H, Kelly TF, Samadani U, Lim L, Rubio S, Overdier DG, et al. Hepatocyte nuclear factor $3 /$ fork head homolog 11 is expressed in proliferating epithelial and mesenchymal cells of embryonic and adult tissues. Mol Cell Biol 1997;17:1626-41.

16. Wierstra I, Alves J. FOXM1, a typical proliferation-associated transcription factor. Biol Chem 2007;388:1257-74

17. Rider ED, Jobe $\mathrm{AH}$, Ikegami $\mathrm{M}$, Yamada $\mathrm{T}$, Seidner $\mathrm{S}$. Antenatal betamethasone dose effects in preterm rabbits studied at 27 days gestation. J Appl Physiol 1990;68:1134-41.

18. Debeer A, Flemmer AW, Lewi PJ, Beheydt S, Buch FD, Zimmermann LJ, et al. Preterm rabbit lung tissue mechanics: Maturational changes and effect of antenatal steroids. Pediatr Pulmonol 2010;45:349-55.

19. Pringle KC. Human fetal lung development and related animal models. Clin Obstet Gynecol 1986;29:502-13.
20. Feldman DM, Carbone J, Belden L, Borgida AF, Herson V. Betamethasone vs dexamethasone for the prevention of morbidity in very-low-birthweight neonates. Am J Obstet Gynecol 2007;197:284.e1-4. 